\title{
Pharmacoeconomic Education for Pharmacy Students in Bosnia and Herzegovina
}

\author{
Tarik Catić1, Selma Skrbo² \\ Society for Pharmacoeconomics and Outcomes Research in Bosnia and Herzegovina - ISPOR BH, Sarajevo, Bosnia and Herzegovina' \\ Faculty for Pharmacy University of Sarajevo, Sarajevo, Bosnia and Herzegovina ${ }^{2}$
}

Corresponding author: Tarik Catic, MSc Pharm, PhD(s). Address: Muhameda Hadzijahica 53, 71000 Sarajevo, B\&H. Tel: +387 61786274.

E-mail: tarikcatic@bih.net.ba

\begin{abstract}
Pharmacoeconomic (PE) is becoming more important in pharmaceutical reimbursement decision and drug evaluation. To ensure its appropriate application, conduction and assessment of studies it is important to have well trained and educated professionals. Pharmaceutical faculties all over the world have established PE in under- and post-graduate curricula's. In this pilot research we examine situation in B\&H. In Bosnia-Herzegovina, education in this field is poor and only one faculty for pharmacy has introduced PE as subject in its program. Objective of this study is to explore understanding of PE and its concept and analysis and to evaluated adopted knowledge among graduate (fifth year/tenth semester) pharmacy students who have listened subject „pharmacoeconomics“ in previous semester. A self-administered questionnaire was developed consisted of 12 questions and survey was conducted among students. Results are analyzed in MS Excel and we used descriptive statistics. Even graduate students have lessons from PE they understand its scope and definition, but do not feel capable for conducting PE studies, but show interest in additional education and getting competencies in this field finding it applicable in their future professional engagements.
\end{abstract}

Key words: pharmacoeconomics, pharmacy education, social pharmacy.

\section{INTRODUCTION}

Pharmacoeconomics is a sub-discipline of the field of health economics, which itself is a relatively new sub-discipline of economics, only formerly appearing in the economics scientific literature since the 1960s. Pharmacoeconomics has been defined as „the description and analysis of the costs of drug therapy to health care systems and society". It identifies, measures and compare costs (resources consumed) and consequences (clinical, economic, humanistic) of pharmaceutical products and services (1).

Pharmacoeconomic studies weigh the cost of alternative drugs and drug regimens against the outcomes they achieve to guide decisions and policies about which drugs should be used in general, which drugs should be paid for by the government or other third party payers, etc. The importance of pharmacoeconomic information to healthcare decision makers will depend upon the viewpoint from which the analysis is conducted. Pharmacoeconomics is needful in pharmaceutical industry, government, and in the private sector for comparing various cost consequences. The two fundamental components of pharmacoeconomic studies are measures of costs and measures of outcomes that are combined into a quantitative measure or ratio (2).

Recently, role of pharmacoeconomics in decision mak- ing process about new pharmaceuticals inclusion into public funding schemes is increasing and becoming more important. The increase in expenditure of health care has prompted many governments, health insurance companies and health providers throughout the world to adopt strategies to manage the high cost of medication, including formulary management and the use of pharmacoeconomics (3).

Development of pharmacoeconomic analysis and concept has led to it application beyond pharmaceuticals assessment. Today, most of developed countries has established concept of health technology assessment which is defined as "the devices, drugs, medical and surgical procedures and knowledge associated with their use in the prevention, diagnosis and treatment of diseases as well as in rehabilitation, and the organizational and supportive systems within which the care is provided"(4). Most of European and developed countries has established national organizations performing pharmacoecnomic evaluations to inform health decision makers and payers about cost-effectiveness of new therapeutics and also those already introduced into national financing programs (5). There is increasing trend in use of pharmacoeconomic studies in European union (EU) countries and more European countries are introducing formal requirements for economic evaluation of new medicines, particularly in the case of innovative products, or in situations in which the 
manufacturer is seeking a premium price (6).

Most developing countries lack policies that encourage the use of economic evaluations in medicine selection for public funding, prioritization of aid or health insurance. In addition, relevant guidelines for reporting pharmacoeconomic analyses are not available in the majority of countries. Most developing countries and low income countries do have National Essential Medicine Lists to guide procurement and donation of medicines in the public sector which is the case in Bosnia and Herzegovina (7). Use of pharmacoeconomic evaluation in Bosnia and Herzegovina is extremely low and performed sporadically by health care decision makers $(8,9)$, even recently introduced legislation proposes pharmacoeconomic evaluation as part of reimbursement file, especially in case of innovative and expensive therapies (10).

In order to ensure financial sustainability of health care system but also to ensure access to novel therapies formal pharmacoeconomic evidence can potentially inform coverage and reimbursement decisions of various health interventions and technologies, as well as the development of formularies and clinical practice guidelines. This is especially important in lower income countries that face more serious constraints on the allocation of their scarce healthcare resources.

Research performed by Singre described three components ought to be in place before the full potential of pharmacoeconomics can be realized: individuals capable of conducting the analyses; a receptive and informed audience of policymakers; and a body of relevant methodology and guidelines (11). Thus, it is imperative for developing countries to build an educational infrastructure of analysts and experts in pharmacoeconomics and to promote the education of pharmacoeconomics at the payer, provider and researcher levels, each according to their needs and tasks.

Pharmacoeconomics education in the developed world is well established and introduced into university curricula in undergraduate but also postgraduate programs. The number of US pharmacy colleges and schools teaching pharmacoeconomics at the professional level increased from $80 \%$ in 1997 to $92 \%$ in 2007, and the colleges and schools that did not offer pharmacoeconomics courses were either new or looking for instructors $(12,13)$. Internationally, the percentage of pharmacy colleges and schools offering pharmacoeconomic education increased from $41 \%$ in 1997 to $52 \%$ in 2004 . $(14,15)$ In this international survey, response from only one existing Faculty for Pharmacy did not reply.

Recently performed pilot study on introduction of pharmacoeconomics and health economics into curriculums of healthcare faculties in Bosnia and Herzegovina showed that only one faculty of medicine and one faculty for pharmacy, out of 22 in the country, included topic as obligatory subject in undergraduate program. Similar situation is when postgraduate curricula are examined (16).

Objective of this study is to explore understanding of pharmacoeconomics and its concept and analysis and to evaluated adopted knowledge among graduate (fifth year/tenth semester) pharmacy students who have listened subject "pharmacoeconomics" in previous semester. To the best of our knowledge, this study is one of the first attempts to comprehensively assess the extent of pharmacoeconomics education in pharmacy and healthcare faculties in Bosnia and Herzegovina.

\section{METHODS}

A self-administered questionnaire was developed consisted of 12 questions; 4 of them with "yes or no" choices, 6 with multiple choices and 2 descriptive questions. Survey has been conducted among pharmacy students at Faculty for pharmacy in Sarajevo. We have selected graduate students on fifth year of study (tenth semester) who have listened and passed exam from subject named "Social pharmacy with pharmacoeconomics". All respondents are informed verbally and also through cover letter before the survey questions, described the rationale behind the survey and that answers will be used for research and improvement of future programs dealing with this topic.

The completed questionnaires were collected and they were coded in Microsoft Excel using descriptive statistics for data analysis.

\section{RESULTS}

The Bachelor of Science in pharmacy (BS Pharm) degree remains the first professional degree required to practice pharmacy in Bosnia and Herzegovina, and is awarded after completion of a 5-year professional program. The oldest Faculty for pharmacy is at University of Sarajevo, where this research is conducted.

Survey has been answered by 54 graduate pharmacy students who have previously listened and passed exam from subject titled "Social pharmacy with pharmacoeconomics". 53 them stated that they are familiar with term "pharmacoeconomics". Majority of respondents, 43 (79.6\%) stated that the have learned about pharmacoeconomics at fifth year of the study, while 11 (20.4\%) did not provide the answer, which is surprising since the lecturers have been held in previous semester. Same percent of $20.4 \%$ of respondents did not answer the question if the subject covering this field is elective or compulsory, which could lead us to the conclusion that maybe they were not participate the lectures or they focused on one part of the subject title referring to "social pharmacy". 41 (75.9\%) stated that the subject dealing with this topic is compulsory and rest quoted it is elective. These discrepancies could be reflection of students' engagement and perception of lectures provided. Questioned whether the subject of pharmacoeconomics / health economics during undergraduate study was separate or part of another subject, $38(70.4 \%)$ answered that it was learned as part of another subject, 12 (22.2\%) did not listen this topic at all, while 4 (7.4\%) answered it was separate subject. Asked to provide name of the subject under which lectures related to pharmacoeconomics/ health economics have been provided, 37 (68.6\%) quoted "Social pharmacy with pharmacoeconomics", and 17 (31.5\%) did not state any other subject.

\begin{tabular}{ll}
\hline $\begin{array}{l}\text { I am able to understand the following pharmacoeconomic } \\
\text { analysis }\end{array}$ & Number (\%) \\
\hline Cost minimisation analysis & $4(7.4)$ \\
\hline Cost effectivenes analysis & $2(3.7)$ \\
\hline Cost utility analysis & $2(3.7)$ \\
\hline Budget impact analysis & $2(3.7)$ \\
\hline Development of pharmacoeconomics models & $1(1.9)$ \\
\hline These terms are not entirely clear / understandable for me & $43(79.6)$ \\
\hline Total & $54(100.0 \%)$ \\
\hline
\end{tabular}

Table 1. Students ability based on previous education on understanding and performing some of pharmacoeconomic analysis 


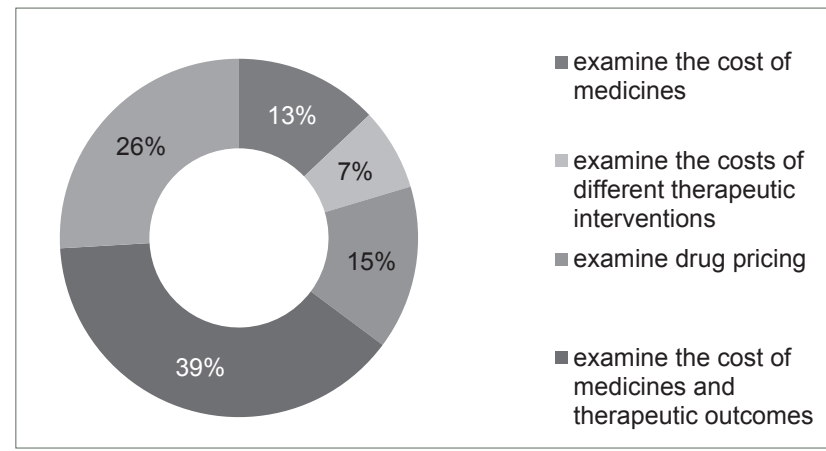

Figure 1. Scope of pharmacoeconomics according to the knowledge of pharmacy students

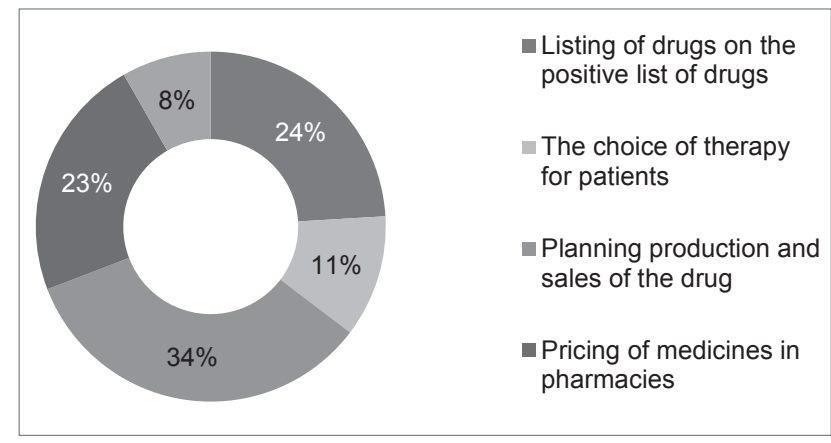

Figure 2. Pharmacoeconomic application according to pharmacy students

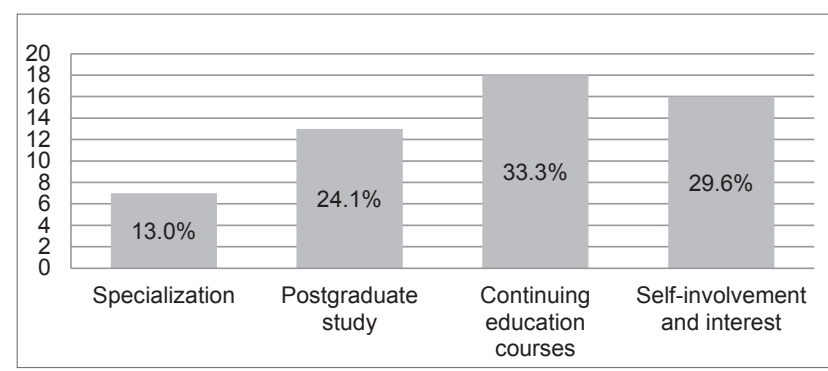

Figure 3. Students`opinion on acquiring additional knowledge in pharmacoeconomics

Figure 1 represents answers on the best explanation (definition) of the scope of pharmacoeconomics according to pharmacy students' knowledge. Majority of them (38.9\%) provide the most accurate definition including cost and outcomes examination, $13.0 \%$ state that main scope is examination of pharmaceuticals costs, and high percentage of students $25.9 \%$ stated that none of offered explanations are not related to the pharmacoeconomic definition and its scope.

When it comes to differentiation of pharmacoeconomics versus health economics, 41 (76.0\%) of students agreed that these two terms are not the same, and 13 (24.0\%) consider it same.

Asked to state where pharmacoeconomics find its application, students were able to select multiple answers and most frequent application according to the responses were in planning of production and sales of the medicines, reimbursement (introduction of medicines into positive lists) and during pharmaceutical pricing process. Details are provided in Figure 2.

Table 1 provides overview on student's ability (capacity) to understand and perform basic pharmacoeconomic analysis based on current knowledge and information. Most of graduate pharmacy students, 45 (83.0\%) consider that pharmacoeconomics as subject should be introduced or included into undergraduate curricula and all of the respondents agree that pharmacoeconomics has use in their work as a future health care professional. Students' opinion about acquiring additional knowledge in pharmacoeconomics are shown in the Figure 3 represents that most of them (70.4\%) are interested in some of postgraduate programs (specialization and postgraduate studies) or through continuing education courses, but also significant number of them , almost one third (29.6\%) would like to gain more knowledge in this filed through self-interest and involvement.

\section{DISCUSSION}

Pharmaceutical education in Bosnia and Herzegovina was mostly limited to basic biomedical and pharmaceutical sciences. There are a few faculties for pharmacy in Bosnia and Herzegovina, private and public (17) and only Faculty for Pharmacy in Sarajevo has subject covering field of pharmacoeconomics introduced into undergraduate curricula. We have conducted this study in order to explore extent of graduate students understanding of the concept but also to explore learning outcome of provided program and lectures. Beside pharmaceutical education, it is important to stress that similar programs should be introduced at other health care faculties - medicine, dentistry and high schools since there is need for newly qualified doctors to have a firm grounding in the principles of safe, suitable, efficacious and cost-effective prescribing (18). Kulkarani conducted research in form of pilot project among medical students and concluded that there is a need for medical undergraduate students to be sensitized on basic concept of pharmacoeconomics. Hence, PE should be introduced in the curriculum of medical undergraduates what would help them to realize the enormous differences in cost of various brands available in the market and will also increase the awareness of indirect cost and intangible cost associated with the drug therapy. (19) There is some intention to introduce concept of education in the field of health economics and pharmacoeconomics in Bosnia and Herzegovina medical and health care faculties, but it is still in its infancy and only a small number of schools are teaching pharmacoeconomics at the undergraduate and graduate levels. (16) In Bosnia and Herzegovina there are professional associations like International Society for Pharmacoeconomics and Outcomes Research Regional Chapter in B\&H (ISPOR BH) which provide some training in this field from health care professionals through seminars and conferences, publications and online modules in Bosnian (20).

In this research we found interesting that most of the students surveyed state that they are familiar with term "pharmacoeconomics" and they make a difference versus "health economics". It is also interested that most of them, even listened or passed exam, do not feel comfortable in conducting and understanding basic pharmacoeconomic methods and analysis. This could be a good signal for future deeper research on structure and time allocation to this topic. It is also interesting that education in this field is not provided under other subjects like pharmacology or clinical pharmacy. This could be one way of increasing awareness and knowledge among health care students since some pharmacoeconomic concepts could be covered and discussed under pharmacology or clinical pharmacy lectures. There is also need for additional training of lecturers included in educational process so they can provide quality education and training. There are only a few researchers in this field who are well educated and trained abroad, according to ISPOR BH databases 
(20). We believe that the adoption of pharmacoeconomics in Bosnia and Herzegovina schools of pharmacy has lagged behind for many reasons. First, the lack of awareness about the existence and importance of pharmacoeconomics on the side of curriculum decision makers (deans and department chairs) poses a barrier to adopting pharmacoeconomics into the curriculum. Second, the lack of experts in this field who reside in Bosnia and Herzegovina, but also neighboring countries, makes it more difficult to recruit instructors who can teach this subject in the pharmacy curriculum. Third, as with any emerging area of education, efforts and resources must be expended to build sound foundations. As it is showed in results, most of students are not familiar with primary application of pharmacoeconomic studies results, stating that it is more suitable for pharmaceutical production and selling plans or pricing of medicines in pharmacy, it is clear that there is a huge room for improvement on clarification of pharmacoeconomic application. This finding also suggests that students are not familiar with pharmaceutical administration and legislation and that this topic are not covered during the study, especially under the subject named Social pharmacy. There is increasing trend of use of pharmacoeconomic analysis and approach when submitting drugs for inclusion of reimbursement list (10) so faculties should prepare pharmacy students with this in order to assure their professional engagement after graduate. Also, faculties could organize short courses on pharmacoeconomics in association with professional association for health care decision makers since there is an evidence that they are not familiar with this terms and not well educated to understand results of provided studies (21).

Most of respondents also show interest in additional education in pharmacoeocnomics through postgraduate courses and programs. There are some intentions of specialization program for pharmacist organized by Federal ministry of Health to introduce specialization called "Pharmaceutical informatics and Pharmacoecnomics" but analyzing program adopted by $\mathrm{MoH}$ there is no enough basic pharmacoeconomic education and there is a lack of pharmacoeconomic analysis education in terms of conducting studies, adopting them to local needs and understanding of study results (22). Based on these results and other studies published in literature we suggest that there is a need to raise awareness about pharmacoeconomics among various stakeholders and also encourage formal pharmacoeconomics education and training. Healthcare professionals in training, such as student pharmacists and physicians, should have formal pharmacoeconomics education as a part of their required coursework and experiential training. The goal would be to develop their ability to apply pharmacoeconomic knowledge to critically evaluate economic evidence when making decisions in their practice. Building a homegrown base of pharmacoeconomics experts could only be accomplished through formal degrees (e.g. doctor of philosophy) and research fellowships, where students learn how to conceptualize pharmacoeconomics at a more advanced level, synthesize new clinical and economic knowledge, develop new methodologies, and assimilate the multidisciplinary knowledge of pharmacoeconomics from its parent disciplines (23).

The appropriate use of credible pharmacoeconomic evidence can help strengthen health systems only when essential structural and regulatory policy measures are being implemented, along with continuous improvement in transparency and accountability within national pharmacy systems.

\section{CONCLUSIONS}

There is a great deficit in the availability of pharmacoeconomics courses in pharmacy schools in Bosnia and Herzegovina at both the undergraduate and graduate levels. Findings from this study suggest that pharmacy students are familiar with terms and basic concepts of pharmacoeconomics, but they do not feel capable to conduct or understand and adopt published studies. They are also missing technical knowledge so they could implement in practice. A unique opportunity exists for well-trained individuals to fill this gap. Providing pharmacoeconomic education to pharmacy students is especially important in an era when evidence-based healthcare decision making and preparing future pharmacist for different field of work. This study is good basic for additional research among other pharmaceutical education institutions and health care faculties in Bosnia and Herzegovina compare results and also conduct similar survey based studies among graduated pharmacist currently working to gain their insight and view on this topic.

\section{REFERENCES}

1. Bootman JL, Townsend RJ, McGhan WF. Principles of Pharmacoeconomics. 2nd ed. Cincinnati OH: Harvey Whitney Books Co., 1996.

2. Gattani G, Patil SB, Kushare AS. Pharmacoeconomics: a review. Asian Journal of Pharmaceutical and Clinical Research. 2009; 2(3): 15-26.

3. Harris A. Using economic evidence in reimbursement decisions for health technologies: experience of 4 countries. Expert Rev. Pharmacoeconom. Outcomes Res. 2001; (1): 7-12.

4. Mubashar S, Tarin E. Health Technology Assessment: Lessons to Learn. Tanaffos. 2006; 5(3): 9-12.

5. Banta D, Jonsson E. History of HTA: Introduction. Int J Technology Assessment in Health Care. 2009; 25(Supp 1): 1-6.

6. Drummond M, Dubois D, Garattini L, Horisberger B, Jönsson B. et al. Current Trends in the Use of Pharmacoeconomics and Outcomes Research in Europe. Value Health. 1999; 2(5): 323-332.

7. Hogerzeil HV. The concept of essential medicines: lessons for rich countries. BMJ. 2004; 329: 1169-1171.

8. Čatić T, Begović B. Overview of HTA Process and Implementation Among Health Stakeholders in Bosni and Herzegovina - Survey Based Research. Value Health. 2011; 14: A356.

9. Čatć T, Martinović I, Begovic B. The role of pharmacoeconomics in medicines reimbursement decision-making in Bosnia and Herzegovina. Folia Medica. 2012; 47(1-Suppl): 50 .

10. Ordinance on criteria for inclusion and development of list of drugs financed by Solidarity fund. Official gazette of Federation of Bosnia and Herzegovina No 36/11. 2011 (Bosnian).

11. Singer ME. Cost-effectiveness analysis, developing nations left behind. Pharmacoeconomics. 2008; 26(5): 359-361.

12. Rascati KL, Conner TM, Draugalis JR. Pharmacoeconomic education in US schools of pharmacy. Am J Pharm Educ. 1998; 62(3): 167-169.

13. Reddy M, Rascati KL, Wahawisan J, Rascati M. Pharmacoeconomic education in US colleges and schools of pharmacy: an update. Am J Pharm Educ. 2008;72(4): 51.

14. Nwokeji ED, Rascati KL. Pharmacoeconomic education in colleges of pharmacy outside of the United States. Am J Pharm Educ. 2005; 69(3): 348-355.

15. Rascati KL, Draugalis JT, Conner T. Pharmacoeconomic education in schools of pharmacy. In: Salek S, editor. Pharmacoeconomics and Outcome Assessment: A Global Issue. Haslemere, UK: University of Wales, Cardiff, 1999: 25-32.

16. Čatić T. Pharmacoeconomic Education for Healthcare Students in Bosnia and Herzegovina. Value Health. 2013 (in publication)

17. Agency for Development of Higher Education and Quality Assurance. <URL:http://hea.gov.ba > (Accessed on August 10 2013)

18. Simon M, Tom W. Teaching safe and effective prescribing in UK Medical school: A core curriculum for tomorrow's doctors. British Med. Pharmacol. 2003; 55(6): 496-503.

19. Kulkarni U, Deshmukh YA, Moghe VV, Rege N, Kate M. Introducing pharmacoeconomics (PE) in medical undergraduate curriculum.Afr. J. Pharm. Pharmacol. 2010; 4(1): 27-30

20. Society for Pharmacoecnomics and Outcomes Research in Bosnia and Herzegovina <URL:http://www.farmakoekonomika.ba >(Accessed on August 10 2013).

21. Čatić T, Begović B. Overview of HTA Process and Implementation Among Health Stakeholders in Bosni and Herzegovina - Survey Based Research. Value in Health. 2011; 14: A356.

22. Federal Ministry of Health.<URL:http://www.fmoh.gov.ba/index.php/usavrsavanja/specijalizacija $>$ (Accessed on August 12 2013).

23. Rascati KL, Drummond MF, Annemans L, Davey PG. Education in pharmacoeconomics: an international multidisciplinary view. Pharmacoeconomics. 2004; 22(3): 139-147. 